\title{
ESENSI UTANG \\ DALAM KONSEP EKONOMI ISLAM
}

\author{
Abdul Aziz \\ Ramdansyah \\ STAIN Gajah Putih Takengon \\ E-mail : azizs_gayo@yahoo.co.id
}

\begin{abstract}
Meeting the needs of life is something that must be done. To meet these needs is constrained because keterbatas money as a tool applicable in the transaction, for which one needs the help of others for the fulfillment of the terms muamalah called the debt. Debt is an obligation for someone to pay if the debt maturity has been up, even the debt shall be the duty of someone since he was alive until he dies. We often hear when the bodies would be buried, who often say is the debt that will be transferred to the heirs of the new corpses to be buried. Seeing this context debt is an important role for someone to pay it off.
\end{abstract}

Kaywords: Debt and Islam Economic

\section{A. Pendahuluan}

Utang piutang merupakan salah satu dari sekian banyak jenis kegiatan ekonomi yang dikembangkan dan berlaku di masyarakat. Sebagai kegiatan ekonomi masyarakat, utang piutang bisa berlaku pada seluruh tingkatan masyarakat baik masyarakat kuno maupun masyarakat modern. Berdasarkan pemikiran ini, utang piutang dapat diperkirakan telah ada dan dikenal oleh masyarakat yang ada di bumi ini ketika mereka berhubungan antara satu orang dengan orang lainnya mempunyai sisi-sisi sosial yang sangat tinggi. 
Dalam konsep Islam, utang piutang merupakan akad (transaksi ekonomi) yang mengandung nilai ta'awun (tolong menolong). Dengan demikian utang piutang dapat dikatakan sebagai ibadah sosial yang dalam pandangan Islam juga mendapatkan porsi tersendiri. Utang piutang juga memiliki nilai luar biasa terutama guna bantu membantu antar sesama yang bagi yang tidak mampu secara ekonomi atau sedang membutuhkan. Keinginan yang begitu baik, maka tujuan utang piutang tolong menolong, transaksi ini terlepas dari unsur komersial dan usaha yang berorientasi pada keuntungan.

Kata utang dalam penyebutanya terdapat dua buah kata, yakni kata dayn dan kata qardh. Dalam tulisan ini penulis akan mencoba membahas beberapa permasalahan yang menyangkut tentang utang dengan melampirkan dalil AlQuran dan Hadis sebagai penguat dalam pembahasannya.

\section{B. Pembahasan}

\section{Utang Dalam Persepektif Islam}

Dalam bahasa Arab, utang merupakan sesuatu yang berada dalam tanggungjawab orang lain. Dayn disebut juga dengan وصف الذ مة (sesuatu yang harus dilunasi atau diselesaikan. Menurut Hanafiyah, dayn termasuk kepada almilk. Utang dapat dikatagorikan pada al-Māl al-Hukmi: "sesuatu yang dimiliki oleh pemberi utang, sementara harta itu berada pada orang yang berutang." Sehingga utang negara adalah milik rakyat dan dipergunakan untuk keperluan rakyat. Selain itu, utang secara bahasa utang juga dapat bermakna memberikan pinjaman. Al Dayn mensyaratkan jangka waktu tertentu dalam pengembalian utang, hal ini yang membedakan al-Qardh yang tidak mensyaratkan jangka waktu tertentu dalam pengembalian utangnya, dayn lebih umum dari al-qardh (Nurul Huda, 2012: 239).

Menurut Abu Al-Kasim kata dayn berarti memberi utang atau berhutang. dan kata qardh memiliki arti apa yang dibayarkan kepada orang lain dari harta dengan syarat mengembalikannya sebagai gantinya (Abu Al-kasim, 233). 
Adapun menurut al-Mu'jam al-Wasid kata dayn adalah adalah utang yang bertempo sedangkan qardh utang yang tidak bertempo (Al-mu'jam al-wasid, 2004: 307). Qardh kamu memberikan harta kepada orang lain dengan mengharapkan pengembalian darinya. Qardhul Hasan berarti memberikan pinjaman tanpa keuntungan atau bunga, ini bisa digunakan untuk yang abstrak baik yang menyangkut kebaikan atau keburukan (Al-Mu'jam Al-Wasid, 2004: 307). Jadi baik kata dayn maupun kata qardh adalah kata yang bermakna utang yang memiliki tempo dan tidak bertempo.

Hutang secara terminologi adalah memberikan harta kepada orang yang akan memanfaatkannya dan mengembalikan ganti rugi dikemudian hari (Abdullah bin Muhammad ath-Thayyar, 2009: 152). Sedangkan menurut Kompilasi Hukum Ekonomi Syariah, hutang adalah penyediaan dana atau tagihan antar lembaga keuangan syariah dengan pihak peminjam untuk melakukan pembayaran secara tunai atau cicilan dalam dalam jangka waktu tertentu. Definisi yang dikemukakan dalam Kompilasi Hukum Ekonomi Syariah bersifat apikatif dalam akad pinjam-meminjam antara nasabah dan Lembaga Keuangan Syariah.

\section{Dasar Hukum berutang}

Hukum Utang piutang pada asalnya diperbolehkan dalam syariat Islam. Bahkan orang yang memberikan utang atau pinjaman kepada orang lain yang sangat membutuhkan adalah hal yang disukai dan dianjurkan, karena di dalamnya terdapat pahala yang besar. Adapun dalil-dalil yang menunjukkan disyariatkannya utang piutang ialah sebagaimana berikut ini:

"Dan tolong-menolonglah kamu dalam (mengerjakan) kebajikan dan takwa, dan jangan tolong-menolong dalam berbuat dosa dan pelanggaran. dan bertakwalah kamu kepada Allah, Sesungguhnya Allah Amat berat siksa-Nya." (Q.S. Al Maidah/5: 2) 
Ayat ini memerintahkan manusia agar saling tolongmenolong sesama manusia, hal ini dikarenakan manusia tidak akan dapat hidup tanpa bantuan orang lain dan selalu membutuhkan orang lain. Niat tolong-menolong yang begitu baik dan ikhlas terkadang akan menimbulkan permasalahan dikemudian hari, Allah telah memberikan peringatan dalam firman Allah dalam surat Al-Baqarah ayat 282:

"Hai orang-orang yang beriman, apabila kamu bermu'amalah tidak secara tunai untuk waktu yang ditentukan, hendaklah kamu menuliskannya, dan hendaklah seorang penulis di antara kamu menuliskannya dengan benar, dan janganlah penulis enggan menuliskannya sebagaimana Allah mengajarkannya, maka hendaklah ia menulis, dan hendaklah orang yang berhutang itu mengimlakkan apa yang akan ditulis itu, dan hendaklah ia bertakwa kepada Allah Tuhannya, dan janganlah ia mengurangi sedikitpun daripada hutangnya. Jika yang berhutang itu orang yang lemah akalnya atau lemah keadaannya atau dia sendiri tidak mampu mengimlakkan, maka hendaklah walinya mengimlakkan dengan jujur. dan persaksikanlah dengan dua orang saksi dari orang-orang lelaki di antaramu. jika tak ada dua oang lelaki, maka boleh seorang lelaki dan dua orang perempuan dari saksi-saksi yang kamu ridhai, supaya jika seorang lupa maka yang seorang mengingatkannya. janganlah saksi-saksi itu enggan memberi keterangan apabila mereka dipanggil; dan janganlah kamu jemu menulis hutang itu, baik kecil maupun besar sampai batas waktu membayarnya. Yang demikian itu, lebih adil di sisi Allah dan lebih menguatkan persaksian dan lebih dekat kepada tidak menimbulkan keraguanmu. Tulislah mu'amalahmu itu, kecuali jika mu'amalah itu perdagangan tunai yang kamu jalankan di antara kamu, maka tidak ada dosa bagi kamu, jika kamu tidak menulisnya. dan persaksikanlah apabila kamu berjual beli; dan janganlah penulis dan saksi saling sulit menyulitkan. jika kamu lakukan yang demikian, maka sesungguhnya hal itu adalah suatu kefasikan pada dirimu, dan bertakwalah kepada Allah; 
Allah mengajarmu; dan Allah Maha mengetahui segala sesuatu."

Ayat ini menjelaskan, bahwa dalam bertransaksi yang dilaksanakan idealnya harus tercatat agar ada pegangan diantara pihak yang bertransaksi sebagai bukti etintik. Pada era sekarang ini, sering terjadi permasalahan dikarenakan tidak ada bukti tertulis, sehingga pihak yang bertransaksi saling menyangkal, hal ini memungkinkan karena memiliki nilai yang menguntungkan pada salah satu pihak sehingga ada pihak yang dirugikan.

\section{Rukun dan syarat Utang}

Adapun yang menjadi syarat dan rukum yang harus dipenuhi dalam utang-piutang adalah sebagai berikut:

a. Sighat

Yang dimaksud sighad akad adalah ijab dan kabul. Tidak ada perbedaan diantara fukaha bahwa ijab kabul itu sah dengan lafaz utang dan dengan satu lafaz yang menunjukan maknanya, seperti kata, "aku memberimu utang", atau "aku mengutangimu. Demikian pula kabul sah dengan semua lafaz yang menunjukkan kerelaan, seperti "aku berutang", "aku menerima" atau "aku ridha".

b. Akad

Akad yang dimaksud adalah akad kedua belah pihak yang melakukan teransaksi yang memberi utang dan pengutang. Adapun syarat-syarat bagi pengutang adalah merdeka, balig, berakal sehat dan pandai yang bisa membedakan baik dan buruk.

c. Harta yang dihutangkan berikut:

Rukun harta yang diutangkan adalah sebagai

1) Harta yang berupa harta yang ada padanya, maksudnya harta yang satu sama lain dalam jenis 
yang sama tidak banyak berbeda yang mengakibatkan perbedaan nilai, seperti uang, barang-barang yang ditukar, ditimbang, ditanam dan yang dihitung.

2) Harta yang diutangkan disyaratkan berupa benda, tidak sah mengutangkan manfaat (jasa).

3) Harta yang diutangkan diketahui, yang diketahui kadarnya dan diketahui sifatnya (Mardani, 2013: 335).

\section{Hadis Nabi yang berkaitan dengan utang}

\section{a. Segera membayar utang}

Perbuatan yang cukup sulit adalah ketika seseorang harus membayar utangnya, sering terjadi perselisihan diantara pihak dikarenakan salah satu pihak ingkar terhadap kesepakatan awal. Padahal membayar utang merupakan kewajiban yang harus dilaksanakan, hal ini tergambar pada hadist Nabi sebagai berikut:

"Telah menceritakan kepada kami 'Abdullah bin Muhammad berkata, telah menceritakan kepada kami 'Utsman bin 'Umar berkata, telah mengabarkan kepada kami Yunus dari Az Zuhri dari 'Abdullah bin Ka'b bin Malik dari Ka'b, bahwa ia pernah menagih hutang kepada Ibnu Abu Hadrad di dalam Masjid hingga suara keduanya meninggi yang akhirnya didengar oleh Rasulullah saw., yang berada di rumah. Beliau kemudian keluar menemui keduanya sambil menyingkap kain gorden kamarnya, beliau bersabda: Wahai Ka'b!" Ka'b bin Malik menjawab: Wahai Rasulullah, aku penuhi panggilanmu. Beliau bersabda: Bebaskanlah hutangmu ini. Beliau lalu memberi isyarat untuk membebaskan setengahnya. Ka'b bin Malik menjawab, sudah aku lakukan wahai Rasulullah." Beliau lalu bersabda (kepada Ibnu Abu Hadrad): Sekarang bayarlah" (HR. Muslim) (Imam Abu Husaini Muslim bin Al-Hajaz An-Naisaburi, Juz. 5: 30).

Hadis di atas menjelaskan bahwa suatu kebajikan apabila melunasi utang dengan sesegera mungkin tanpa 
harus di tagih-tagih oleh pemberi utang, namun tidak jarang kita jumpai di tengah masyarakat kita, banyak orang yang berutang, mereka enggan membayarkan kewajibannya ketika waktu pelunasan sudah jatuh tempo. Kewajiban segera membayar utang, termasuk utang seseorang yang meninggal dunia, hal ini dilakukan belumlah boleh dikuburkan sebelum selesai utang atau adanya pengakuan utang dari keluarga yang ditinggalkan, hal ini sesuai dengan hadis Rasulullah:

"Telah menceritakan kepada kami Musaddad telah mengabarkan kepada kami Bisyir bin al Mufadhdhal telah menceritakan kepada kami Husain al Mu'alim dari 'Atha' dari Jabir ra., berkata; Ketika terjadi perang Uhud, pada suatu malamnya bapakku memanggilku seraya berkata,: "Tidaklah aku melihat diriku (menduga) melainkan aku akan menjadi orang yang pertama-tama gugur diantara para sahabat Nabi saw., (dalam peperangan ini) dan aku tidak meninggalkan sesuatu yang berharga bagimu sepeninggalku melainkan diri Rasulullah saw., dan aku mempunyai hutang, maka lunasilah dan berilah nasehat yang baik kepada saudara-saudaramu yang perempuan". Pada pagi harinya kami dapati bapakku adalah orang yang pertama gugur dan dikuburkan bersama dengan yang lain dalam satu kubur. Setelah itu perasaanku tidak enak dengan membiarkan dia bersama yang lain, maka kemudian aku keluar setelah enam bulan lamanya dari hari pemakamannya dan aku dapati jenazah bapakku masih utuh sebagaimana hari dia dikebumikan dan tidak ada yang berubah padanya kecuali sedikit pada ujung bawah telinganya" (HR. Bukhari) (Abu Abdullah Muhammad bin Ismail al-Bukhary al-Jami' alShahih, 414-415).

\section{b. Tambahan dalam membayar utang}

Tambahan ketika membayar utang adalah tidak wajib, namun tambahan itu adalah suatu kesadaran dari seseorang yang berhutang, ia boleh menambahkan dari utang pokoknya dengan syarat tambahan tersebut tidak 
diucapkan diawal akad, hal ini pernah dilakukan Nabi dalam hadisnya:

"Telah menceritakan kepada kami Khallad bin Yahya berkata, telah menceritakan kepada kami Mis'ar berkata, telah menceritakan kepada kami Muharib bin Ditsar dari Jabir bin 'Abdullah berkata, "Aku datang menemui Nabi saw., saat beliau berada di masjid -Mis'ar berkata, "Menurutku Jabir berkata, 'Saat waktu dluha.'- Jabir bin 'Abdullah berkata, "Beliau bersabda: "Shalatlah dua rakaat." Ketika itu beliau mempunyai hutang kepadaku. Maka beliau membayarnya dan memberi tambahan kepadaku" (HR. Bukhari)

Hadis di atas menjelaskan bahwa Nabi muhammad SAW, mengembalikan hutangnya dengan memberikan tambahan sebagai rasa ucapan syukur atau terimakasih kepada si pemberi pinjaman. Meskipun demikian, tidak boleh bagi pemberi pinjaman untuk mensyaratkan bahwa ketika nanti mengembalikan utang maka harus diberi tambahan atau kelebihan. Kalau memberi tambahan itu dilakukan dengan sukarela.

Adapun kalau tambahan tersebut yang disyaratkan dalam akad, maka para ulama sepakat bahwa itu hukumnya haram. Jika memberikan tambahan yang melebihi jumlah hutangnya saat membayar hutang juga tidak diperbolehkan, hal itu bukan berarti juga diperbolehkan memberikan hadiah dan sejenisnya sebelum hutangnya sendiri di bayar, hal itu sama dengan suap yang jelas-jelas tidak dihalalkan (Al-Imam Muhammad AsSyaukani, 1994: 657).

\section{Memberi Kemudahan bagi yang kesulitan membayar utang}

Bagi seseorang yang memiliki kesulitan dalam membayar utangnya, maka hendaknya memberikan kemudahan dan jangan malah menambah beban bagi yang berhutang, hal ini sesuai dengan hadis Nabi: 
"Telah menceritakan kepada kami Yahya bin Yahya at Tamimi dan Abu Bakr bin Abu Syaibah dan Muhammad bin al Ala al-Hamdani dan lafadh ini milik Yahya dia berkata; telah mengabarkan kepada kami, dan berkata yang lainnya, telah menceritakan kepada kami Abu Mu'awiyah dari al A'masy dari Abu Shalih dari Abu Hurairah dia berkata; Rasulullah saw. telah bersabda: Barang siapa membebaskan seorang mukmin dari suatu kesulitan dunia, maka Allah akan membebaskannya dari suatu kesulitan pada hari kiamat. Barang siapa memberi kemudahan kepada orang yang berada dalam kesulitan, maka Allah akan memberikan kemudahan di dunia dan akhirat. Barang siapa menutupi aib seorang muslim, maka Allah akan menutup aibnya di dunia dan akhirat. Allah akan selalu menolong hamba-Nya selama hamba tersebut menolong saudaranya sesama muslim. Barang siapa menempuh jalan untuk mencari ilmu, maka Allah akan memudahkan jalan ke surga baginya. Tidaklah sekelompok orang berkumpul di suatu masjid (rumah Allah) untuk membaca Al Qur'an, melainkan mereka akan diliputi ketenangan, rahmat, dan dikelilingi para malaikat, serta Allah akan menyebut-nyebut mereka pada malaikat-malaikat yang berada di sisi-Nya. Barang siapa yang ketinggalan amalnya, maka nasabnya tidak juga meninggikannya. Telah menceritakan kepada kami Muhammad bin Abdullah bin Numair telah menceritakan kepada kami bapakku demikian juga diriwayatkan dari jalur lainnya, dan telah menceritakannya kepada kami Nashr bin Ali al-Jahdhami telah menceritakan kepada kami Abu Usamah mereka berkata; telah menceritakan kepada kami al A'masy telah menceritakan kepada kami Ibnu Numair dari Abu Shalih. Sebagaimana di dalam hadits Abu Usamah Telah menceritakan kepada kami Abu Shalih dari Abu Hurairah dia berkata; Rasulullah saw., berkata dengan lantang, sebagaimana Hadits Abu Mu'awiyah, hanya saja di dalam Hadits Abu Usamah tidak disebutkan; memberi kemudahan kepada orang yang kesusahan" (HR.Tirmizi) (Imam al-hafizh Muhammad bin Isa bin Tsaurah at-Tirmizi: 336). 


\section{Prinsip Utang}

Utang merupakan suatu yang biasa terjadi dalam kehidupan begitu pula dalam ajaran Islam. Hal ini merupakan sunatullah yang sudah digariskan oleh Allah. Bahkan pada awal ayat surat Al-Baqarah/2: 282, disebutkan bahwa jika seorang yang beriman ingin berutang kepada pihak lain dalam jangka waktu tertentu, maka hendaklah ia mencatatnya. Hal ini menunjukan bahwa utang adalaha hal yang diperbolehkan selama memenuhi sejumlah prinsip dan etika pokok. Adapun prinsip-prinsip utang yang harus diperhatikan ialah:

a) Harus disadari bahwa utang itu merupakan alternatif terakhir ketika segala usaha untuk mendapatkan dana secara halal dan tunai mengalami kebuntuan. Ada unsur keterpaksaan di dalamnya dan bukan unsur kebiasaan. Ini merupakan dua hal yang berbeda. Keterpaksaan mencerminkan semangat membangun kemandirian dan berusaha mengoptimalkan potensi yang ada semaksimal mungkin. Namun karena keterbatasan yang tidak sanggup diatasi, akhirnya terpaksa memilih jalan utang.

b) Jika terpaksa berutang, jangan berutang di luar kemampuan. Inilah yang dalam istilah syariah disebut dengan ghalabatid dayn atau terbelit utang. Ghalabatid dayn ini akan menimbulkan efek yang besar, yaitu gharir rijal atau mudah dikendalikan pihak lain. Oleh karena itu Rasulullah saw., selalu memanjatkan doa agar beliau senantiasa dilindungi dari penyakit ghalabatid dayn yang menyebabkan harga diri atau izzah menjadi hilang (Nurul Huda, 2012: 260-261).

c) Jika utang telah dilakukan, harus ada niat untuk membayarnya. Harus memiliki komitmen untuk mengembalikan utang (Sukri Iska, 2012: 179). Memperlambat membayar utang bagi yang mampu merupakan sebuah kezaliman, sehingga diperbolehkan untuk mempermalukannya. Dalam konteks mikro, akan sangat mudah akan sangat mudah menerapkan prinsip ini. Misalnya, pengusaha yang tidak mau membayar utang boleh saja dipermalukan dengan cara menyita asetnya, 
dilarang berpergian ke luar negeri atau menghukum dengan hukuman yang berat.

\section{Simpulan}

Semua aktifitas yang dilakukan oleh seorang muslim, hendaklah dilakukan secara sungguh-sungguh, agar apa yang dilakukannya akan mendapatkan nilai yang sempurna di dunia dan akherat. Dalam kegiatan muamalah yang dilakukan, hendaklah memperhatikan utang, utang adalah sebagai metode terakhir dalam meraih nilai dan bila mengandung nilai keterpaksaan dan idealnya berusaha agar jangan terlibat di dalamnya. Utang dayn tidak ada tambahan dan murni dikembalikan sebagaimana pada saat dipinjam, sedangkan utang qardh adalah utang piutang yang dilakukan pada perbankan, hal ini merupakan pembiyaan yang memiliki unsur bisnis.

Bagi seorang muslim yang terpaksa berutang karena suatu hal, maka hendaklah memperhatikan utang, jangan utang dijadikan faktor utama yang bisa menyengsarakan kita di dunia dan akherat, karena tidak jarang kita jumpai karena persoalan utang, kehidupan seseorang menjadi tidak bahagia dan bahkan menjadi permasalahan yang tidak selesai-selasai. Padahal utang itu akan dipertanggungjawabkan dari diri kita sejak hidup hingga kita mati. 


\section{Daftar Pustaka}

Departemen Agama RI, , Alqur'an dan Terjemahnya, Depok, Sabiq, 2009

Abdillah, Abu Muhammad bin Ismail al Buhari. al Jami' asy Shahih, Qohira: Muktabah asy-Syalafiyah, tt.

Abu Husaini, Imam Muslim bin al-Hajaz an-Naisaburi. al Jami' as-Shahih (t.tp, tt).

Al-Husain, Abu al-Kasim bin Muhammad. al-Mufradad fi Gharibil quran, t.tp: Nazar Mustafa al-Baz, tt.

Al-Mu'jam al-Wasid , Mesir: Maktabah Suru' Dawliyah, 2004.

Al-hafizh, Imam Muhammad bin Isa bin Tsaurah at-Tirmizi. Sunan at-Tirmizi, Riyadh: Ma'tabah al-Ma'arif, tt.

Ath-Thayyar, Abdullah bin Muhammad. Ensiklopedi figh Muamalah Dalam Pandangan 4 mazhab, Yogyakarta: Maktabah al-Hanif, 2009.

Iska, Sukri. Sistem Perbankan Sayriah di Indonesia dama Persperspektik Fikih Ekonomi , Yogyakarta: Fajar Media Press, 2012.

Kompilasi Hukum Ekonomi Syariah pasal 30 ayat (36).

Mardani. Fiqh Ekonomi Syariah, Jakarta: Kencana, 2013.

Huda, Nurul at.al. Dalam Keuangan Publik Islami; Pendekatan Teoritis dan Sejarah, Jakarta: Kencana, 2012.

Muhammad Asy-Syaukani, Al-Imam. Nailul Autar, terj. Adib Bisri Mustafa, Semarang: Asy Syifa, 1994.

Muhammad, Abu Abdullah bin Ismail al-Bukhary. al-Jami' alShahih, Qahirah: Maktabah al-Salafiyah, tt. 